\title{
Screening and optimization of low-cost medium for Pseudomonas putida Rs-198 culture using RSM
}

\author{
Yanjie Peng, Yanhui He, Zhansheng Wu, Jianjiang Lu, Chun Li \\ School of Chemistry and Chemical Engineering, Key Laboratory for Chemical Materials of Xinjiang \\ Uygur Autonomous Region, Shihezi University, Shihezi, P.R. China.
}

Submitted: May 15, 2013; Approved: April 17, 2014.

\begin{abstract}
The plant growth-promoting rhizobacterial strain Pseudomonas putida Rs-198 was isolated from salinized soils from Xinjiang Province. We optimized the composition of the low-cost medium of $P$. putida Rs-198 based on its bacterial concentration, as well as its phosphate-dissolving and indole acetic acid (IAA)-producing capabilities using the response surface methodology (RSM), and a mathematical model was developed to show the effect of each medium component and its interactions on phosphate dissolution and IAA production. The model predicted a maximum phosphate concentration in medium containing $63.23 \mathrm{mg} / \mathrm{L}$ inorganic phosphate with $49.22 \mathrm{~g} / \mathrm{L}$ corn flour, $14.63 \mathrm{~g} / \mathrm{L}$ soybean meal, $2.03 \mathrm{~g} / \mathrm{L} \mathrm{K}_{2} \mathrm{HPO}_{4}, 0.19 \mathrm{~g} / \mathrm{L} \mathrm{MnSO}_{4}$ and $5.00 \mathrm{~g} / \mathrm{L} \mathrm{NaCl}$. The maximum IAA concentration $(18.73 \mathrm{mg} / \mathrm{L})$ was predicted in medium containing $52.41 \mathrm{~g} / \mathrm{L}$ corn flour, $15.82 \mathrm{~g} / \mathrm{L}$ soybean meal, $2.40 \mathrm{~g} / \mathrm{L} \mathrm{K}_{2} \mathrm{HPO}_{4}, 0.17 \mathrm{~g} / \mathrm{L} \mathrm{MnSO}_{4}$ and $5.00 \mathrm{~g} / \mathrm{L} \mathrm{NaCl}$. These predicted values were also verified through experiments, with a cell density of $10^{13} \mathrm{cfu} / \mathrm{mL}$, phosphate dissolution of $64.33 \mathrm{mg} / \mathrm{L}$, and IAA concentration of $18.08 \mathrm{mg} / \mathrm{L}$. The excellent correlation between predicted and measured values of each model justifies the validity of both the response models. The study aims to provide a basis for industrialized fermentation using $P$. putida Rs-198.
\end{abstract}

Key words: Pseudomonas putida Rs-198, Low-cost medium, Phosphorus-dissolving, IAA, Response surface methodology.

\section{Introduction}

Salinization of soil is a serious problem and is increasing steadily in many parts of the world, in particular in arid and semiarid areas (Al-Karaki, 2006). Xinjiang province, located in northwest China, a semi-arid region, is one of the largest hubs of cotton planting. However, increasingly serious soil salinization in the cultivated layer results in substantial losses of cotton yields (Wu et al., 2012). The rate of ground water evaporation and plant transpiration is so high that salt in the groundwater continuously moves toward the cultivation layer (Clercq et al., 2009). Soil salinization has become a major factor limiting crop yields. In recent years, a new approach has been developed to improve the growth of plants and protect them from soil salinity stress, by treating crop seeds and seedlings with plant growth-promoting bacteria (PGPR) (Egamberdieva, 2012;
Yue et al., 2007). PGPR are root-colonizing bacteria in the rhizosphere of numerous plant species. They have the ability to colonize and establish a relationship with plants to increase biomass, root growth, and commercial yield (Whipps, 2001; Tang et al., 2009).

PGPR reportedly promote plant rooting, growth, and nutrient absorption, as well as enhance photosynthesis (Ahmad et al., 2005). P. putida Rs-198 was isolated from alkaline soil and identified based on its physiologic and biochemical properties, as well as sequence analysis its $16 \mathrm{~S}$ rDNA by Yao et al. (2010). The effects of P. putida Rs-198 on cotton seedling growth under salt stress have been studied. Results indicated that $P$. putida Rs- 198 protects plants against salt stress and promotes cotton seedling growth. Further analysis showed that $P$. putida Rs-198 increases the absorption of $\mathrm{Mg}^{2+}, \mathrm{K}^{+}$, and $\mathrm{Ca}^{2+}$, decreases $\mathrm{Na}^{+}$uptake from the soil, and also improves the production of endoge- 
nous indole acetic acid (IAA) content of cotton seedlings under salt stress. A research team investigated the phosphate-dissolving capability of $P$. putida Rs-198 and found that the bacterial strain increases the soluble phosphate content of the soil, thereby improving phosphate absorption.

The high price of beef extract and peptone used in common media has increased the production costs of $P$. putida Rs-198. However, industrial of P. putida Rs-198 production can be made economical by utilizing low-cost media such as agricultural by-products (corn flour, soybean meal) (Ozdemir et al., 2009). Several kinds of inexpensive organic and inorganic nitrogen sources and corn steep liquor were evaluated for their potential to replace more expensive nitrogen sources derived from Bacto-peptone and yeast extract by Saha (2006). The bacterium produced mannitol using soy peptone and corn steep liquor was more than that of using Bacto-peptone and yeast extract. Pereira et al. (2010) also reported that statistical experimental designs were used to develop a medium based on corn steep liquor and other low-cost nutrient sources for high-performance very high gravity (VHG) ethanol fermentations by Saccharomyces cerevisiae. This study provides valuable insights into cost-effective nutritional supplementation of industrial fuel ethanol VHG fermentations.

We optimized the medium using the response surface methodology (RSM) to obtain a high bacterial concentration, phosphate-dissolving capability, and IAA content in the low-cost medium. The RSM is increasingly used for various phases of fermentation optimization. RSM is a collection of mathematical and statistical techniques that are useful for the modeling and analysis of problems, in which a response of interest is influenced by several variables (Liu and Wang, 2007) and the objective is to optimize this response. First, we screened different concentrations of the carbon source, the nitrogen source, and inorganic salts. Second, we used the Box-Behnken Design (BBD) test in Design-Expert 7.0 (trial version) to design an experiment to measure the phosphate-dissolving capability and IAA content in low-cost medium (Qin et al., 2012).

The main objectives of this study are to determine the optimal low-cost medium components for soluble phosphate and IAA production using $P$. putida Rs-198, and to understand the relationships among the medium constituents (corn flour, soybean meal and inorganic salts), soluble phosphate production and IAA production. This study will provide a foundation for the industrialized fermentation of P. putida Rs-198, thereby providing a method for highdensity culture.

\section{Materials and Methods}

\section{Bacterial strain and culture medium}

The strain P. putida Rs-198 sued in this study was isolated previously from salinized soil in Xinjiang province,
China (Yao et al., 2010) and was grown on Nutrient Agar (NA) liquid medium (beef extract $5 \mathrm{~g}$, peptone $10 \mathrm{~g}, \mathrm{NaCl}$ $5 \mathrm{~g}, \mathrm{H}_{2} \mathrm{O} 1000 \mathrm{~mL}$, pH 7.0-7.2). Pure cultures of the Rs-198 were preserved in NA liquid medium with shaking at $170 \mathrm{rpm}$ and at $30^{\circ} \mathrm{C}$ for $48 \mathrm{~h}$. Final cell concentration of $P$. putida Rs-198 maintained at $10^{13} \mathrm{cfu} / \mathrm{mL}$ by constantly keeping it at $4{ }^{\circ} \mathrm{C}$.

\section{Single-factor experiment}

Given the high cost of beef extract and peptone, corn flour and soybean meal were chosen as the $\mathrm{C}$ and $\mathrm{N}$ source for the study (Tang et al., 2004). The primary $P$. putida Rs-198 inoculums $(1 \mathrm{~mL})$ was inoculated into $100 \mathrm{~mL}$ of culture medium containing $10,30,50$, and $70 \mathrm{~g} / \mathrm{L}$ of corn flour as the sole $\mathrm{C}$ source in $250 \mathrm{~mL}$ conical flask at $30^{\circ} \mathrm{C}$ and $170 \mathrm{rpm}$ for $72 \mathrm{~h}$. Similarly, $1 \mathrm{~mL}$ of the primary inoculum was inoculated into culture medium containing 5 , 10,15 , and $20 \mathrm{~g} / \mathrm{L}$ soybean meal as the sole $\mathrm{N}$ source, $\mathrm{MgSO}_{4}(0.2 \mathrm{~g} / \mathrm{L}), \mathrm{K}_{2} \mathrm{HPO}_{4}(2 \mathrm{~g} / \mathrm{L}), \mathrm{MnSO}_{4}(0.2 \mathrm{~g} / \mathrm{L})$, $\mathrm{CaCO}_{3}(1 \mathrm{~g} / \mathrm{L})$, and $\mathrm{FeCl}_{3}(0.2 \mathrm{~g} / \mathrm{L})$ were used as sources of inorganic salts (Wu et al., 2008). The initial cells concentration in different low-cost mediums were determined as $6.7 \times 10^{10} \mathrm{cfu} / \mathrm{mL}$ by counting the colony-forming units present on NA agar plates after serial dilution for overnight incubation at $30^{\circ} \mathrm{C}$. After $72 \mathrm{~h}$ of cultivation, the cell density, phosphate-dissolving capability, and IAA production of $P$. putida Rs-198 were measured. As we all know, corn flour contains carbohydrates, protein, fat, carotene, riboflavin and other nutrients. Soybean meal contains protein, lysine, tryptophan, methionine, cystine and other nutrients. These nutrients are very useful in the growth of bacterial fermentation.

\section{Measurement of inorganic phosphate-dissolving capability of $P$. putida Rs-198}

Inorganic phosphate-solubilizing activity was measured by plate and broth assay at $30^{\circ} \mathrm{C}$. Pikovskaya's medium (PVK) was used to measure calcium phosphate $\left[\mathrm{Ca}_{3}\left(\mathrm{PO}_{4}\right)_{2}\right]$-solubilizing activity (Chang and Yang, 2009). $P$. putida Rs-198 seed liquid was cultivated in medium containing different concentrations of corn flour, soybean meal, and inorganic salts for $72 \mathrm{~h}$. One percent of the primary inoculum was inoculated into $30 \mathrm{~mL}$ of PVK medium in $100 \mathrm{~mL}$ conical flask and incubated at $30^{\circ} \mathrm{C}$ and $170 \mathrm{rpm}$ for 2 days. After 2 days, the samples were collected and centrifuged at $10,000 \mathrm{rpm}$ for $10 \mathrm{~min}$. The soluble phosphate concentrations in the supernatant were determined using the molybdate blue colorimetric method (Son et al., 2006).

\section{Measuring the ability of $P$. putida Rs-198 to secrete IAA}

After $72 \mathrm{~h}$ of incubation, the bacterial cells in the different culture media were collected by centrifugation $(10,000 \mathrm{~g}, 10 \mathrm{~min})$. The IAA concentrations in the culture 
supernatants were determined using the Salkowski method (Glickmann and Dessaux, 1995). This colorimetric technique was performed according to Pilet and Chollet (1970) using reagent $\mathrm{R} 1$, which consisted of $12 \mathrm{~g}$ of $\mathrm{FeCl}_{3}$ per liter of $7.9 \mathrm{M} \mathrm{H}_{2} \mathrm{SO}_{4}$. One milliliter of the supernatant was added to $1 \mathrm{~mL}$ of Salkowski's reagent and mixed well in a 3 $\mathrm{mL}$ spectrophotometer cuvette. The mixture was left in the dark for $30 \mathrm{~min}$ at room temperature and the absorbance at $530 \mathrm{~nm}$ was recorded. A standard curve was prepared from serial dilutions of $5 \mathrm{mM}$ IAA stock solution. The IAA concentration in each culture medium was determined by comparison with the standard curve (Yue et al., 2007).

\section{RSM experimental design and statistical analysis}

The data obtained at each step were analyzed using the commercial optimization software Design-Expert 7.0. A Box-Behnken (1960) factorial design was used to optimize phosphate solubilization and IAA production. In the preliminary experiments, we evaluated the suitability of the corn flour (carbon source), soybean meal (nitrogen source), and inorganic salt concentrations. Therefore, the four factors were corn flour $\left(x_{1} 50 \mathrm{~g} / \mathrm{L}\right)$, soybean meal $\left(x_{2} 15 \mathrm{~g} / \mathrm{L}\right)$, $\mathrm{K}_{2} \mathrm{HPO}_{4}\left(x_{3} 2 \mathrm{~g} / \mathrm{L}\right)$, and $\mathrm{MnSO}_{4}\left(x_{4} 0.2 \mathrm{~g} / \mathrm{L}\right)$. The range and levels of the variables investigated in this study are given in Table 1 .

A mathematical model was developed to describe the relationships between the process indices (soluble phosphate production and IAA production) and the medium component contents in the second-order equation. The soluble phosphate production and the IAA production of $P$. putida Rs-198 were multiply regressed with respect to the fermentation parameters using the least squares method as follows:

$$
y=\beta_{0}+\sum \beta_{i} x_{i}+\sum \beta_{i i} x_{i}^{2}+\sum \beta_{i j} x_{i} x_{j}
$$

where $y$ is the predicted response variable; $\beta_{0}, \beta_{i}, \beta_{i i}$, and $\beta_{i}$, are the constant regression coefficients of the model; and $x_{i}$ and $x_{j} x_{j}(\mathrm{x}=1,4 ; j=1,4, i ? j)$ represent the independent variables (medium components) in the form of coded values. The accuracy and predictive ability of the polynomial model was evaluated using the coefficient of determination $R^{2}$. Table 2 gives the Box-Behnken design matrix and the changes in soluble phosphate and IAA.

Table 1 - Experimental range and levels of the independent variables.

\begin{tabular}{lccc}
\hline Independent variables $(\mathrm{g} / \mathrm{L})$ & \multicolumn{3}{c}{ Range and levels } \\
\cline { 2 - 4 } & -1 & 0 & 1 \\
\hline $\mathrm{x}_{1}$ & 40 & 50 & 60 \\
$\mathrm{x}_{2}$ & 10 & 15 & 20 \\
$\mathrm{x}_{3}$ & 1 & 2 & 3 \\
$\mathrm{x}_{4}$ & 0.1 & 0.2 & 0.3 \\
\hline
\end{tabular}

Note: $\mathrm{x}_{1}$ : Corn flour; $\mathrm{x}_{2}$ : soybean meal; $\mathrm{x}_{3}: \mathrm{K}_{2} \mathrm{HPO}_{4} ; \mathrm{x}_{4}: \mathrm{MnSO}_{4}$.

\section{Results and Discussion}

\section{Effect of corn flour concentration on the $P$. putida Rs-198 culture}

During recent years, PGPR have attained so much attention of agricultural researchers due to their high efficiency in growth promotion and resistance induction in plants even under the salinity stress of soil and environment (Guo et al., 2010; Nadeem et al., 2010; Yang et al., 2009). Beef extract and peptone are commonly used as microbiologic culture media. However, they are expensive and unsuitable for industrialized $P$. putida Rs-198 culture. In this study, the optimal low-cost culture medium for $P$. putida Rs-198 was obtained by determining the phosphate solubilization and IAA production.

The number of viable cells in the culture media with different corn flour concentrations $(10,30,50$, and $70 \mathrm{~g} / \mathrm{L})$ were similar (about $10^{12} \mathrm{cfu} / \mathrm{mL}$ ) (Figure 1). This result indicates that corn flour concentration has little effect on bacterial growth.

P. putida Rs-198 produced over $25 \mathrm{~mm}$ halo zone around their colonies on the PKV medium within $4 \mathrm{~d}$ of incubation. This observation showed that P. putida Rs-198 had phosphate solubilization ability (Wu et al., 2012). To determine the optimal corn flour concentration for insoluble phosphate solubilization, shake flask cultures were carried out with different corn flour concentrations in the medium. The $P$. putida Rs-198 under the different corn flour concentrations had different inorganic phosphatedissolving capabilities. Figure 1 shows that the soluble phosphate production using medium containing $50 \mathrm{~g} / \mathrm{L}$ corn flour was $55 \mathrm{mg} / \mathrm{L}$, which is higher than under other corn flour concentrations. On the other hand, many PGPR strains have been identified as having the ability to produce the plant growth regulators indole-3-acetic acid, cytokinin and/or other plant hormones in the rhizosphere (Kailidag et al., 2007) that could improve the growth of plants and alleviate the effect of growth inhibitors by declining abscisic acid content of plants (Patten and Glick, 2002). Our study showed that the IAA concentration in the supernatant of the medium containing $50 \mathrm{~g} / \mathrm{L}$ corn flour was about $18 \mathrm{mg} / \mathrm{L}$, which is also higher than other corn flour concentrations. The soluble phosphate $(55 \mathrm{mg} / \mathrm{L})$ and IAA concentrations $(18 \mathrm{mg} / \mathrm{L})$ in the $50 \mathrm{~g} / \mathrm{L}$ of corn flour medium are also higher than the other concentrations. This might be due to $50 \mathrm{~g} / \mathrm{L}$ corn flour play a role as effective nutrient for $P$. putida Rs-198 growth and secrete IAA as reported by Yun et al. (2004). A similar result was obtained by Tang et al. (2004), who used barley flour $\left(x_{1}=67.6 \mathrm{~g} / \mathrm{L}\right)$ and corn flour $\left(x_{2}=48.9 \mathrm{~g} / \mathrm{L}\right)$ as the center points to optimize medium composition with a central composite design. Therefore, 50 $\mathrm{g} / \mathrm{L}$ of corn flour was selected as the $\mathrm{C}$ source for the low-cost medium for subsequent tests. 
Table 2 - Box-Behnken design matrix and the responses of soluble P and IAA.

\begin{tabular}{|c|c|c|c|c|c|c|}
\hline \multirow[t]{2}{*}{ Test number } & \multicolumn{4}{|c|}{ Factors and their levels } & \multirow{2}{*}{$\begin{array}{c}\mathrm{Y}_{1} \\
\text { phosphate solubilization }\end{array}$} & \multirow{2}{*}{$\begin{array}{c}\mathrm{Y}_{2} \\
\text { IAA production }\end{array}$} \\
\hline & $\mathrm{x}_{1}$ & $\mathrm{x}_{2}$ & $\mathrm{x}_{3}$ & $\mathrm{x}_{4}$ & & \\
\hline 1 & 1 & 1 & 0 & 0 & 58.01 & 17.63 \\
\hline 2 & -1 & 0 & 0 & 1 & 55.66 & 13.46 \\
\hline 3 & 0 & -1 & 1 & 0 & 51.83 & 16.59 \\
\hline 4 & -1 & 1 & 0 & 0 & 50.25 & 14.97 \\
\hline 5 & 0 & 1 & 0 & 1 & 46.44 & 15.85 \\
\hline 6 & 0 & 1 & 0 & -1 & 51.56 & 16.57 \\
\hline 7 & 0 & 1 & 1 & 0 & 51.81 & 19.43 \\
\hline 8 & 1 & 0 & 1 & 0 & 44.00 & 21.27 \\
\hline 9 & 0 & -1 & -1 & 0 & 51.69 & 12.01 \\
\hline 10 & 1 & 0 & 0 & -1 & 56.50 & 18.55 \\
\hline 11 & 0 & 0 & 0 & 0 & 63.90 & 17.10 \\
\hline 12 & 0 & -1 & 0 & 1 & 55.98 & 13.99 \\
\hline 13 & 0 & 0 & -1 & 1 & 55.88 & 12.69 \\
\hline 14 & -1 & 0 & -1 & 0 & 50.00 & 12.34 \\
\hline 15 & 0 & 0 & -1 & -1 & 55.59 & 15.47 \\
\hline 16 & 1 & 0 & -1 & 0 & 52.27 & 16.62 \\
\hline 17 & -1 & -1 & 0 & 0 & 51.97 & 11.86 \\
\hline 18 & 1 & -1 & 0 & 0 & 52.24 & 15.74 \\
\hline 19 & 0 & 0 & 1 & -1 & 55.54 & 19.17 \\
\hline 20 & 0 & -1 & 0 & -1 & 57.77 & 13.20 \\
\hline 21 & 0 & 0 & 0 & 0 & 62.90 & 17.10 \\
\hline 22 & 0 & 0 & 0 & 0 & 62.90 & 17.10 \\
\hline 23 & 1 & 0 & 0 & 1 & 51.93 & 17.63 \\
\hline 24 & -1 & 0 & 1 & 0 & 59.91 & 17.01 \\
\hline 25 & 0 & 0 & 1 & 1 & 53.80 & 16.66 \\
\hline 26 & 0 & 1 & -1 & 0 & 53.87 & 13.46 \\
\hline 27 & -1 & 0 & 0 & -1 & 55.61 & 14.63 \\
\hline
\end{tabular}

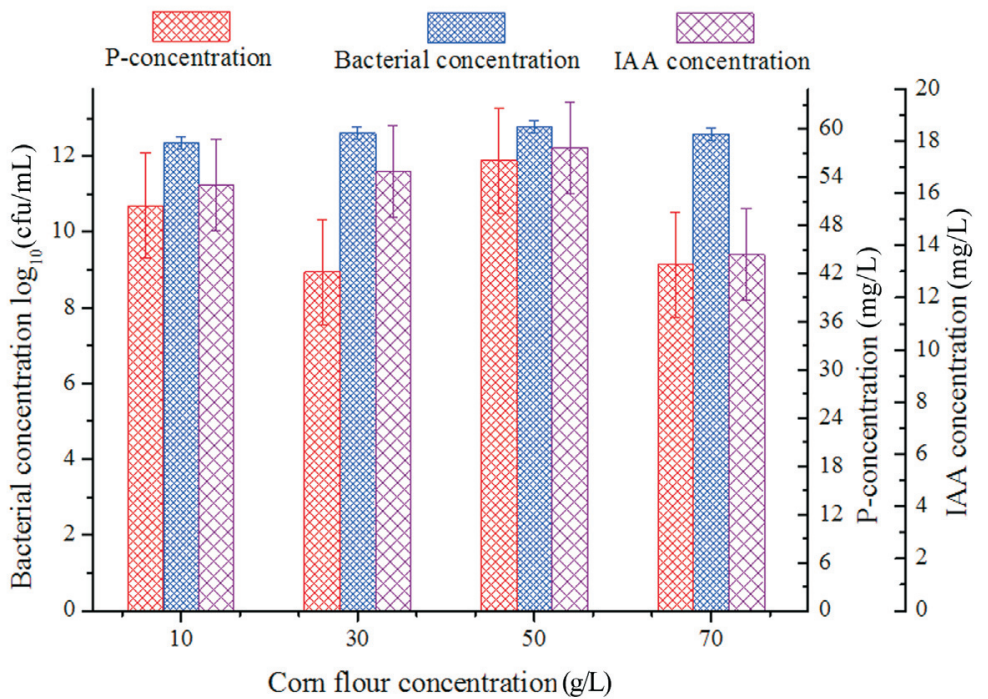

Figure 1 - Changes in the cell density, phosphate-dissolving capability, and IAA production of $P$. putida Rs-198 in medium containing different corn flour concentrations. The cultures were performed with $1 \%$ of the inoculum at $30{ }^{\circ} \mathrm{C} 72 \mathrm{~h}$ on a rotary shaker at $170 \mathrm{rpm}$. Each value is the mean of triplicate experiments. 


\section{Effect of soybean meal concentration on $P$. putida Rs-198 culture}

Various amounts $(5,10,15,20 \mathrm{~g} / \mathrm{L})$ of soybean meal as the $\mathrm{N}$ source were separately added to the medium to assess their effects on insoluble phosphate solubilization. Similar to the above, previous studies revealed that Rs-198 could secrete IAA (Yao et al., 2010). Figure 2 shows that the productions of soluble phosphate $(53 \mathrm{mg} / \mathrm{L})$ and IAA (19 mg/L) by strain P. putida Rs-198 in low-cost medium including $15 \mathrm{~g} / \mathrm{L}$ soybean meal are higher than others. Joo and Chang (2005) also reported that the optimal medium contained $15 \mathrm{~g} / \mathrm{L}$ soybean meal according to the optimization experiments. Therefore, $15 \mathrm{~g} / \mathrm{L}$ of soybean meal was selected as the $\mathrm{N}$ source for low-cost medium in subsequent tests.

\section{Effect of different inorganic salts on P. putida Rs-198 culture}

To determine the effect of the increase in the amounts of various salts $\left(\mathrm{MgSO}_{4}, \mathrm{~K}_{2} \mathrm{HPO}_{4}, \mathrm{MnSO}_{4}, \mathrm{CaCO}_{3}, \mathrm{FeCl}_{3}\right)$ on cell density, insoluble phosphate solubilization, and IAA production of $P$. putida Rs-198, various concentrations of each salt were added to the low-cost medium (Son et al., 2006). Figure 3 shows that the soluble phosphate and the IAA content of the medium containing $\mathrm{K}_{2} \mathrm{HPO}_{4}$ were about $60 \mathrm{mg} / \mathrm{L}$ and $13 \mathrm{mg} / \mathrm{L}$, respectively. Meanwhile, the soluble phosphate and IAA content of the medium containing $\mathrm{MnSO}_{4}$ were about $58 \mathrm{mg} / \mathrm{L}$ and $14 \mathrm{mg} / \mathrm{L}$, respectively. In addition, there were very little differences between effects of inorganic salts as $\mathrm{K}_{2} \mathrm{HPO}_{4}, \mathrm{MnSO}_{4}, \mathrm{MgSO}_{4}$, $\mathrm{CaCO}_{3}$ and $\mathrm{FeCl}_{3}$ in the medium on cell density of the culture liquid. Moreover, the phosphate-dissolving and IAA production capability of $P$. putida Rs-198 cultured in me- dium containing these two salts are more than those with the other inorganic salts. Therefore, we selected the $\mathrm{K}_{2} \mathrm{HPO}_{4}$ and $\mathrm{MnSO}_{4}$ as the inorganic salts in the medium for culture in subsequent tests.

\section{Low-cost medium further optimized using RSM}

\section{Optimization of phosphate solubilization}

The Box-Behnken design and the corresponding experimental data are shown in Table 2. Table 3 shows the analysis of variance for the experiment. In this study, the phosphate-dissolving capability of $P$. putida Rs-198 was determined and analysis of variance (ANOVA) was used to obtain the interaction between the process variables and the responses. The coefficient of determination $\left(R^{2}\right)$ of phosphate solubilization was 0.7978 , which indicates that $79.78 \%$ of the variability in the response can be accounted by the model.

The polynomial model for soluble phosphate $Y_{P}$ was regressed by considering the significant terms and expressed as Eq. (2).

$$
\begin{aligned}
& Y_{P}=623.10+1.87 x_{1} x_{2}-4.54 x_{1} x_{3}-5.09 x_{1}^{2}- \\
& 5.71 x_{2}^{2}-5.36 x_{3}^{2}-3.36 x_{4}^{2}
\end{aligned}
$$

The model reveals that the quadratic terms $\left(x_{1}^{2}, x_{2}^{2}, x_{3}^{2}\right.$ and $\left.x_{4}^{2}\right)$ have a significant but negative effect $(\mathrm{p}<0.01)$ on $Y_{P}$.

Figure 4 presents the 2-D contour plot (A) and the 3 -D response surface $(B)$ of the combined effects of corn flour and soybean meal on the soluble phosphate. Soluble phoaphate was sensitive to even small alteration in corn flour and soybean meal concentrations. The soluble phosphate significantly increased with increasing corn flour and soybean meal concentrations.

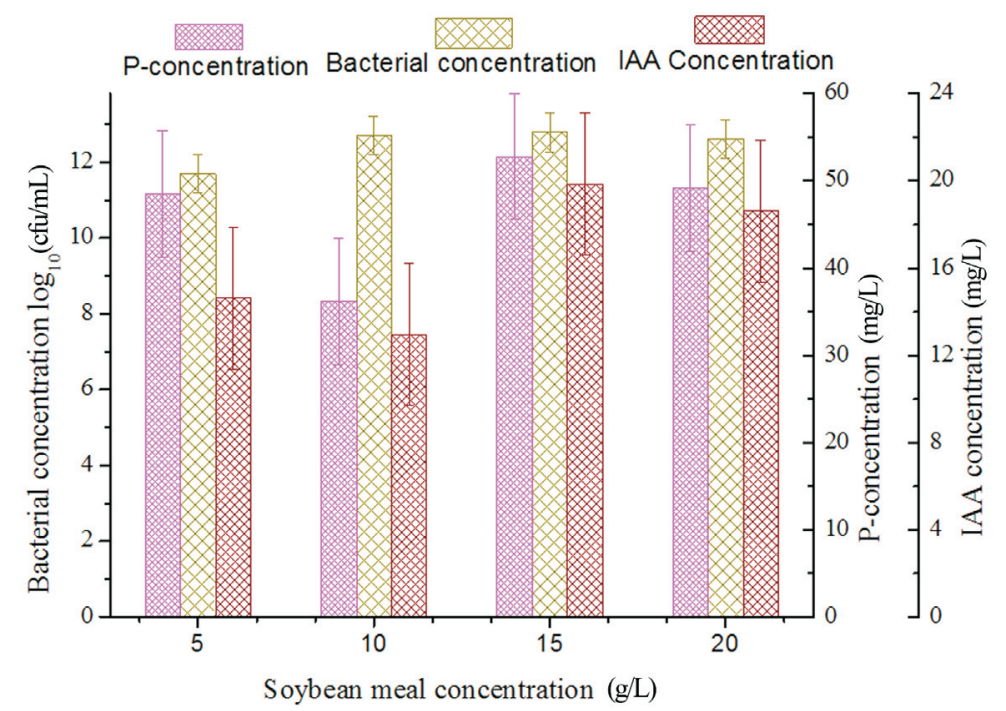

Figure 2 - Changes in the cell density, phosphate-dissolving capability, and IAA production of $P$. putida Rs-198 in medium containing different soybean meal concentrations. The cultures were performed with $1 \%$ of the inoculum at $30{ }^{\circ} \mathrm{C} 72 \mathrm{~h}$ on a rotary shaker at $170 \mathrm{rpm}$. Each value is the mean of triplicate experiments. 


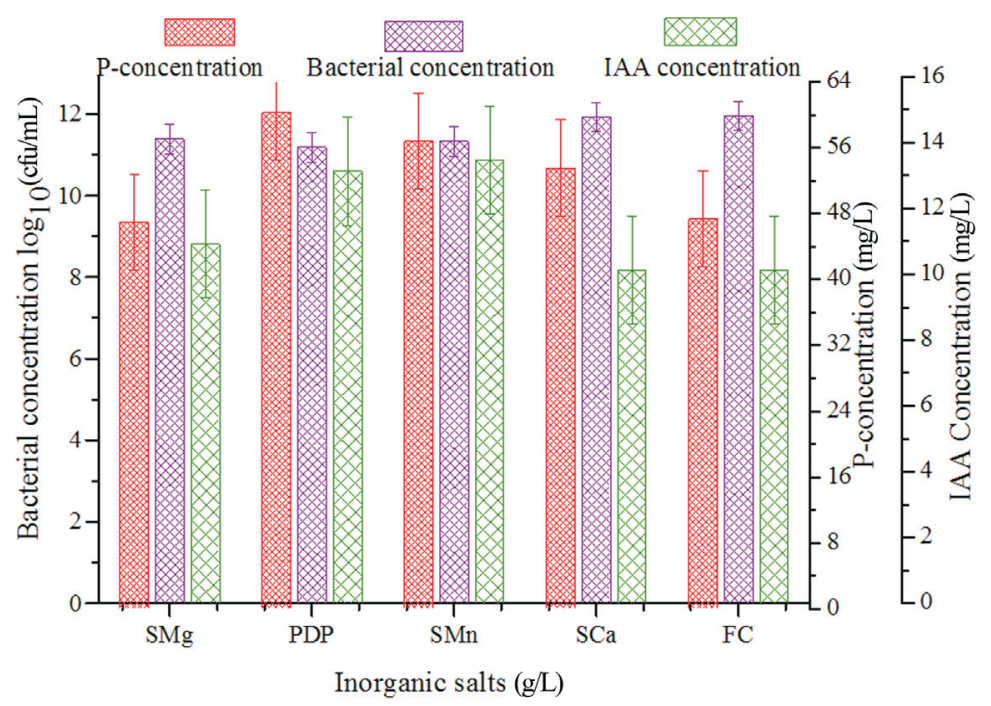

Figure 3 - Changes in the cell density, phosphate-dissolving capability, and IAA production of P. putida Rs-198 in medium containing different inorganic salts concentrations ( $\mathrm{SMg}: \mathrm{MgSO}_{4}, \mathrm{PDP}: \mathrm{K}_{2} \mathrm{HPO}_{4}, \mathrm{SMn}_{\mathrm{MnSO}}$, $\mathrm{SCa}: \mathrm{CaCO}_{3}, \mathrm{FC}: \mathrm{FeCl}_{3}$ ). The cultures were performed with $1 \%$ of the inoculum at $30^{\circ} \mathrm{C} 72 \mathrm{~h}$ on a rotary shaker at $170 \mathrm{rpm}$. Each value is the mean of triplicate experiments.

Table 3 - Analysis of variance (ANOVA) of the fitted quadratic polynomial model for optimizing soluble phosphate production.

\begin{tabular}{lcccc}
\hline Regression & DF & Sum of squares & F value & Pr $>$ F \\
\hline Linear & 4 & 27.84 & 0.25 & 0.9069 \\
Quadratic & 4 & 420.69 & 10.46 & 0.0004 \\
Cross-product & 6 & 107.01 & 10.63 & 2.8435 \\
Lack of fit & 10 & 140.02 & 70.01 & 0.0005 \\
Pure error & 4 & 0.80 & 3.95 & 0.0075 \\
Total model & 14 & 555.54 & very significant significant \\
$\mathrm{R}^{2}=0.7978 ;$ adj. $\mathrm{R}^{2}=0.5956$ & & & very significant \\
\hline
\end{tabular}

A)

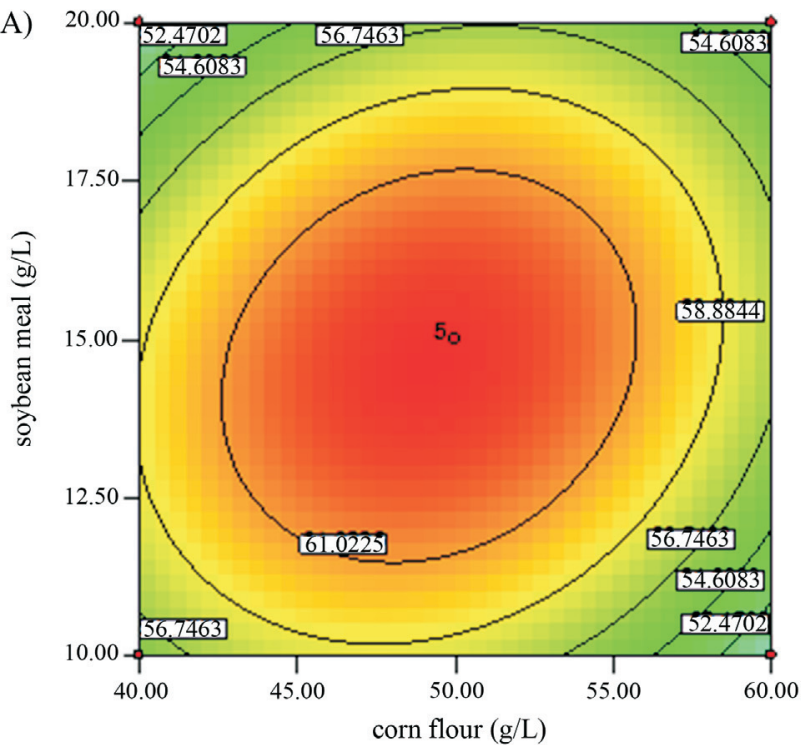

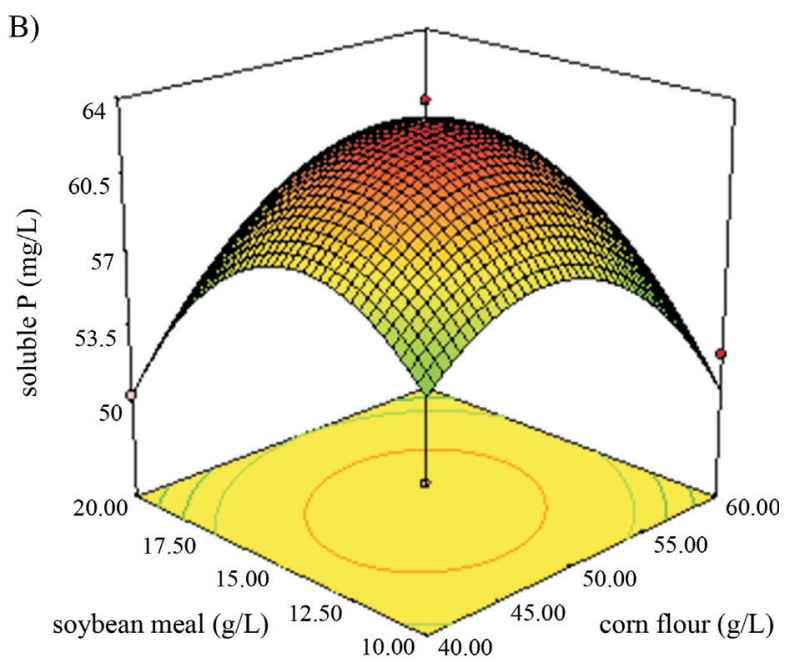

B)

Figure 4 - 2D Contour plot (A) and 3D response surface $(B)$ of the combined effects of corn flour and soybean meal concentration (g/L) on the soluble phosphate. 
The predicted the maximum soluble phosphate was $63.23 \mathrm{mg} / \mathrm{L}$ when cultures with $49.22 \mathrm{~g} / \mathrm{L}$ corn flour, $14.63 \mathrm{~g} / \mathrm{L}$ soybean meal, $2.03 \mathrm{~g} / \mathrm{L} \mathrm{K}_{2} \mathrm{HPO}_{4}$, and $0.19 \mathrm{~g} / \mathrm{L}$ $\mathrm{MnSO}_{4}$.

\section{Optimization of IAA production}

Table 4 shows the analysis of variance for the experiment. The coefficient of determination $\left(R^{2}\right)$ was shown was 0.9625 , which indicates that $96.25 \%$ of the variability in the response can be accounted by the model. The polynomial model for IAA concentration $Y_{I A A}$ was regressed by considering the significant terms and expressed as Eq. (3).

$$
\begin{aligned}
& Y_{\text {IAA }}=17.10+1.93 x_{1}+1.21 x_{2}+2.30 x_{3}- \\
& 0.61 x_{4}-1.59 x_{2}^{2}-0.77 x_{4}^{2}
\end{aligned}
$$

The model reveals that $\mathrm{K}_{2} \mathrm{HPO}_{4}$ concentration $\left(x_{3}\right)$ significantly affected $Y_{I A A}(\mathrm{p}<0.01)$ as indicated by the highest coefficient, followed by corn flour $\left(x_{1}\right)$ and soybean meal $\left(x_{2}\right)$. The positive coefficients $x_{1}, x_{2}$ and $x_{3}$ indicate the linearity of $Y_{I A A}$ increase. However, quadratic terms $\left(x_{2}^{2}\right.$ and $\left.x_{4}^{2}\right)$ and $\mathrm{MnSO}_{4}$ concentration $\left(x_{4}\right)$ had negative effects.
The 2-D contour plot (A) and the 3-D response surface $(B)$ of the combined effects of corn flour and soybean meal on IAA production are shown in Figure 5. The analysis reveals a maximum IAA production was $18.73 \mathrm{mg} / \mathrm{L}$ when the medium contained $52.46 \mathrm{~g} / \mathrm{L}$ corn flour, $15.82 \mathrm{~g} / \mathrm{L}$ soybean meal, $2.40 \mathrm{~g} / \mathrm{L} \mathrm{K}_{2} \mathrm{HPO}_{4}$ and $0.17 \mathrm{~g} / \mathrm{L} \mathrm{MnSO}_{4}$.

\section{Verification of the models}

The calculated optimum concentrations of soluble phosphate were verified, with the maximum soluble phosphate concentration at $66.33 \mathrm{mg} / \mathrm{L}$ within $48 \mathrm{~h}$, which is consistent with the predicted value $(63.23 \mathrm{mg} / \mathrm{L})$ (Figure 6). This result suggests that the proposed model (Equation 2) is also efficient for soluble phosphate production. Under the calculated optimal culture composition, the IAA production reached $19.32 \mathrm{mg} / \mathrm{L}$ at $72 \mathrm{~h}$, which is consistent with the predicted value $(18.73 \mathrm{mg} / \mathrm{L})$. This result suggests that the proposed model (Eq. (3)) is also efficient for IAA production. The excellent correlation between predicted and measured values of these experiments justifies the validity of the response model and the existence of an optimum point (Liu and Wang, 2007).

\begin{tabular}{|c|c|c|c|c|c|}
\hline Regression & DF & Sum of squares & F value & $\operatorname{Pr}>F$ & \\
\hline Linear & 4 & 129.95 & 30.69 & $<0.0001$ & very significant \\
\hline Quadratic & 4 & 18.13 & 10.89 & 0.0003 & very significant \\
\hline Cross-product & 6 & 1.45 & 3.50 & 3.5956 & \\
\hline Lack of fit & 10 & 5.82 & & & \\
\hline Pure error & 4 & 0 & & & \\
\hline Total model & 14 & 149.53 & 25.68 & $<0.0001$ & very significant \\
\hline $\mathrm{R}^{2}=0.9625$; adj. $\mathrm{R}^{2}=0.9250$ & & & & & \\
\hline
\end{tabular}

Table 4 - Analysis of variance (ANOVA) for the fitted quadratic polynomial model for optimization of IAA production.
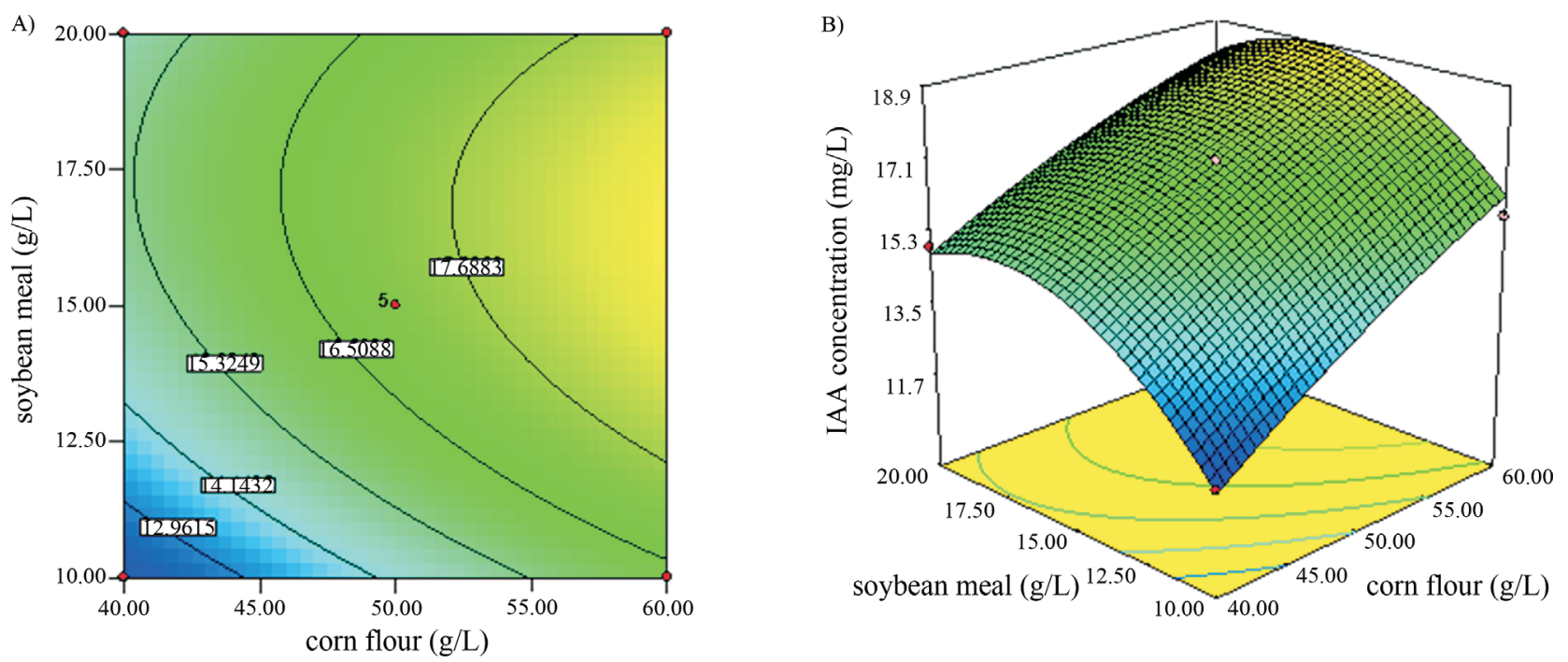

Figure 5 - 2D Contour plot (A) and 3D response surface (B) of the combined effects of corn flour and soybean meal concentration (g/L) on the IAA content. 


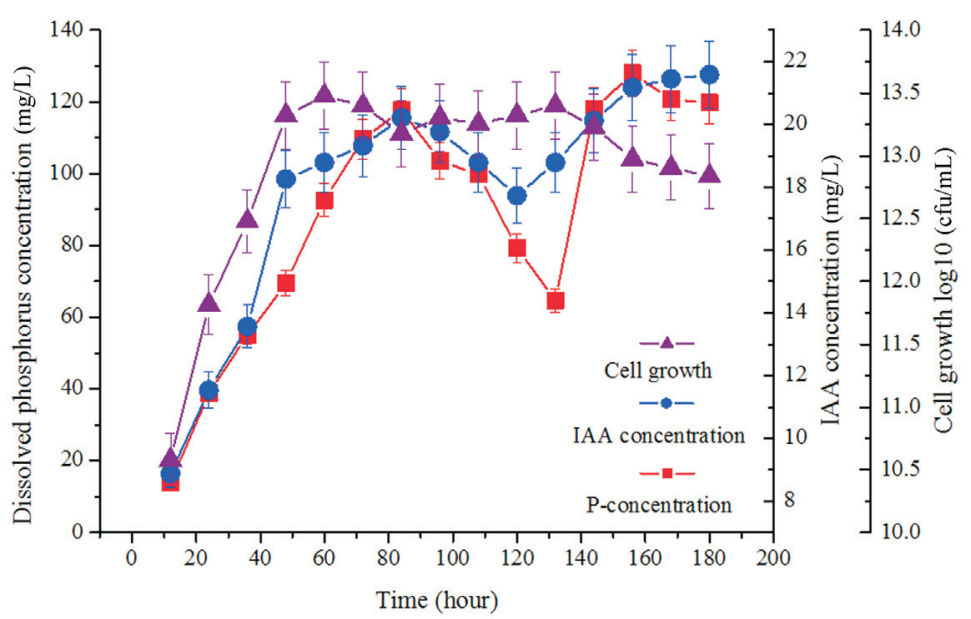

Figure 6 - Phosphate concentration in medium A, and IAA production and cell growth in medium B during P. putida Rs-198 growth. Medium A (in grams per liter): corn flour, $49.22 \mathrm{~g} / \mathrm{L}$; soybean meal, $14.63 \mathrm{~g} / \mathrm{L} ; \mathrm{K}_{2} \mathrm{HPO}_{4}, 2.03 \mathrm{~g} / \mathrm{L} ; \mathrm{MnSO}_{4}, 0.19 \mathrm{~g} / \mathrm{L}$. Medium B (in grams per liter): corn flour, $52.41 \mathrm{~g} / \mathrm{L}$; soybean meal, $15.82 \mathrm{~g} / \mathrm{L} ; \mathrm{K}_{2} \mathrm{HPO}_{4}, 2.4 \mathrm{~g} / \mathrm{L} ; \mathrm{MnSO}_{4}, 0.17 \mathrm{~g} / \mathrm{L}$. The cultivations were performed with $1 \%$ of the inculcated amount at $30^{\circ} \mathrm{C}$ and $170 \mathrm{rpm}$ for $180 \mathrm{~h}$ in a rotary shaker. Each value is the mean of triplicates. Error bars indicate the standard error of the mean $(\mathrm{n}=5)$.

The cells growing in medium $\mathrm{B}(52.41 \mathrm{~g} / \mathrm{L}$ corn flour; $15.82 \mathrm{~g} / \mathrm{L}$ soybean meal; $2.4 \mathrm{~g} / \mathrm{L} \mathrm{K}_{2} \mathrm{HPO}_{4} ; 0.17 \mathrm{~g} / \mathrm{L}$ $\mathrm{MnSO}_{4}$ ) reached the stationary phase after $48 \mathrm{~h}$. The biomass of culture medium remained relatively stable during P. putida Rs-198 growth. The maximum dissolved phosphate produced during $P$. putida Rs-198 culture was $118 \mathrm{mg} / \mathrm{L}$, which was observed after $84 \mathrm{~h}$ of incubation. The amount of dissolved phosphate decreased to $65 \mathrm{mg} / \mathrm{L}$ after $132 \mathrm{~h}$, indicating that the sole $\mathrm{P}$ source in medium is used during cell growth, and the soluble phosphate precipitated into its insoluble state. Similar phenomena were also observed by Chang and Yang (2009) that eight strains with phosphorus-dissolving capability had a wide range concentration of phosphorus from 4.1 to $370.2 \mathrm{mg} / \mathrm{L}$ in PVK broth during $10 \mathrm{~d}$ at $25^{\circ} \mathrm{C}$.

The bacteria which able to synthesize IAA are widely distributed in plant rhizosphere (Ahmad et al., 2005; Barazani and Friendman, 1999). Figure 6 shows that the IAA content of the low-cost medium supernatant continued to increase to $20 \mathrm{mg} / \mathrm{L}$ but then decreased to $17 \mathrm{mg} / \mathrm{L}$, which may be due attributed to the depletion of IAA during the growth of $P$. putida Rs-198. Some bacteria reportedly produce and degrade IAA during growth, such as Pseudomonas putida 1290 (Johan et al., 2005).

\section{Conclusions}

The effects of the low-cost medium components on the phosphate solubilization and the IAA production of $P$. putida Rs-198 were studied. The polynomial model for soluble phosphate $Y_{P}$ was regressed by considering the significant terms and expressed as:

$$
\begin{aligned}
& Y_{P}=623.10+1.87 x_{1} x_{2}-4.54 x_{1} x_{3}-5.09 x_{1}^{2}- \\
& 5.71 x_{2}^{2}-5.36 x_{3}^{2}-3.36 x_{4}^{2}
\end{aligned}
$$

The polynomial model for IAA concentration $Y_{I A A}$ was regressed by considering the significant terms and expressed as:

$$
\begin{aligned}
& Y_{I A A}=17.10+1.93 x_{1}+1.21 x_{2}+2.30 x_{3}- \\
& 0.61 x_{4}-1.59 x_{2}^{2}-0.77 x_{4}^{2}
\end{aligned}
$$

In addition, these predicted values were also verified through experiments, with a cell density of $10^{13} \mathrm{cfu} / \mathrm{mL}$, phosphate dissolution of $64.33 \mathrm{mg} / \mathrm{L}$, and IAA concentration of $18.08 \mathrm{mg} / \mathrm{L}$. The excellent correlation between predicted and measured values of each model justifies the validity of both the response models. In conclusion, RSM is an effective method for maximizing phosphate solubilization and IAA production and it provides useful information for large-scale high-density culture of P. putida Rs-198 for phosphate solubilization and IAA production.

\section{Acknowledgments}

This study was financially supported by National Natural Science Foundation of China (31260022) and Science and Technology Fund Projects of Shihezi University (RCZX201122 and 2013ZRKXJQ01).

\section{References}

Ahmad F, Ahmad I, Khan MS (2005) Indole acetic acid production by the indigenous isolates of Azotobacter and Fluorescent Pseudomonas in the presence and absence of tryptophan. Turk J Biol 29:29-34.

Al-Karaki GN (2006). Nursery inoculation of tomato with arbuscular mycorrhizal fungi and subsequent performance under irrigation with saline water. Sci Hortic-Amsterdam 109:1-7. 
Barazani OZ, Friendman J (1999) Is IAA the major root growth factor secreted from plant growth mediating bacteria? J Chem Ecol 25:2397-2406.

Box GP, Behnken DW (1960) Some new three level designs for the study of quantitative variables. Technometrics $2: 456$ 475.

Chang CH, Yang SS (2009) Thermo-tolerant phosphate-solubilizing microbes for multi-functional biofertilizer preparation. Bioresource Technol 100:1648-1658.

Clercq WD, Meirvenne MV, Fey MV (2009) Prediction of the soil-depth salinity-trend in a vineyard after sustained irrigation with saline water. Agr Water Manage 96:395-404.

Egamberdieva D (2012) Pseudomonas chlororaphis: a salttolerant bacterial inoculant for plant growth stimulation under saline soil conditions. Acta Physiol Plant 34:751-756.

Glickmann E, Dessaux Y (1995) A critical examination of the specificity of the Salkowski reagent for indolic compounds produced by phytopathogenic bacteria. Appl Environ Microb 61:793-796.

Guo LQ, Shi DC, Wang DL (2010) The key physiological response to alkali stress by the alkali-resistant halophyte puccinellia tenuiflora is the accumulation of large quantities of organic acids and into the rhyzosphere. J Agron Crop Sci 196:123-135.

Johan H, Leveaul J, Lindow SH (2005) Utilization of the plant hormone indole-3-acetic acid for growth by Pseudomonas putida strain 1290. Appl Environ Microb 71:2365-2371.

Joo HS, Chang CS (2005) Production of protease from a new alkalophilic Bacillus sp. I-312 grown on soybean meal: optimization and some properties. Process Biochem 40:12631270.

Karlidag H, Esitken A, Turan M, Sahin F (2007) Effects of root inoculation of plant growth promoting rhizobacteria (PGPR) on yield, growth and nutrient element contents of leaves of apple. Sci Hortic-Amsterdam 114:16-20.

Liu GQ, Wang XL (2007) Optimization of critical medium components using response surface methodology for biomass and extracellular polysaccharide production by Agaricus blazei. Appl Microbiol Biot 74:78-83.

Nadeem SM, Zahir ZA, Naveed M, Asghar HN, Arshad M (2010) Rhizobacteria capable of producing ACC-deaminase may mitigate salt stress in wheat. Soil Sci Soc Am J 74:533-542.

Ozdemir S, Giiven K, Baysal Z, Uyar F (2009) Screening of various organic substrates and the development of a suitable low-cost fermentation medium for the production of $\alpha$-amylase by Bacillus subtilis. Food Technol Biotech 47:264-369.

Patten CL, Glick BR (2002) Role of Pseudomonas putida indoleacetic acid in development of the host plant root system. Appl Environ Microb 68:3795-3801.
Pereira FB, Guimaraes PMR, Teixeira JA, Domingues L (2010) Optimization of low-cost medium for very high gravity ethanol fermentations by Saccharomyces cerevisiae using statistical experimental designs. Bioresource Technol 101:7856-7863.

Pilet PE, Chollet R (1970) Surle dosage colorimetrique de l'acide indolylacetique. CR Acad Sci Ser D 271:1675-1678.

Qin SH, Wu ZS, Rasool A, Li C (2012) Synthesis and characterization of slow-release nitrogen fertilizer with water absorbency: Based on poly (acrylic acid-acrylic amide)/Na-bentonite. J Appl Polym Sci 126:1687-1697.

Saha BC (2006) A low-cost medium for mannitol production by Lactobacillus intermedius NRRL B-3693. Appl Microbiol Biotechnol 72:676-680.

Son HJ, Park GT, Cha MS, Heo MS (2006) Solubilization of insoluble inorganic phosphates by a novel salt-and $\mathrm{pH}$-tolerant Pantoea agglomerans R-42 isolated from soybean rhizosphere. Bioresource Technol 97:204-210.

Tang XJ, He GQ, Chen QH, Zhang XY, Mokhtar AMA (2004) Medium optimization for the production of thermal stable $\beta$-glucanase by Bacillus subtilis ZJF-1A5 using response surface methodology. Bioresource Technol 93:175-181.

Tester M, Davenport R (2003) $\mathrm{Na}^{+}$tolerance and $\mathrm{Na}^{+}$transport in higher plants. Ann Bot 91:503-527.

Whipps JM (2001) Microbial interactions and biocontrol in the rhizosphere. J Exp Bot 52:487-511.

Wu Y, Tao J, Zhao SF (2008) Optimizing the fermentation conditions for Bacillus sp. combination CL-8 thalli with cooperative and synergistic action and its biocontrol efficacy. Trans CSAE 24:204-208.

Wu ZS, Yue HT, Lu JJ, Li C (2012) Characterization of rhizobacterial strain Rs-2 with ACC deaminase activity and its performance in promoting cotton growth under salinity stress. World J Microbiol Biotechnol 28:2383-2393.

Yang J, Kloepper JW, Ryu CM (2009) Rhizosphere bacteria help plants tolerate abiotic stress. Trends Plant Sci 14:1-4.

Yao LX, Wu ZS, Zheng YY, Kaleem I, Li C (2010) Growth promotion and protection against salt stress by Pseudomonas putida Rs-198 on cotton. Eur J Soil. Biol 46:49-54.

Yue HT, Mo WP, Li C, Zheng YY, Li H (2007) The salt stress relief and growth promotion effect of Rs-5 on cotton. Plant Soil 297:139-145.

Yun JS, Wee YJ, Kim JN, Ryu HW (2004) Fermentative production of DL-lactic acid from amylase-treated rice and wheat brans hydrolyzate by a novel lactic acid bacterium, Lactobacillus sp. Biotechnol Lett 26:1613-1616.

All the content of the journal, except where otherwise noted, is licensed under a Creative Commons License CC BY-NC. 